\title{
Clinical implementation of electric impedance tomography in the treatment of ARDS: a single centre experience
}

\author{
Serge J. H. Heines ${ }^{1}\left({ }^{10}\right.$. Ulrich Strauch ${ }^{1}$ Marcel C. G. van de Poll ${ }^{1,2,3} \cdot$ Paul M. H. J. Roekaerts ${ }^{1,4}$. \\ Dennis C. J. J. Bergmans ${ }^{1}$
}

Received: 12 January 2018 / Accepted: 27 May 2018 / Published online: 29 May 2018

(c) The Author(s) 2018

\begin{abstract}
To report on our clinical experience using EIT in individualized PEEP titration in ARDS. Using EIT assessment, we optimized PEEP settings in 39 ARDS patients. The EIT PEEP settings were compared with the physicians' PEEP settings and the PEEP settings according to the ARDS network. We defined a PEEP difference equal to or greater than $4 \mathrm{~cm}_{2} \mathrm{O}$ as clinically relevant. Changes in lung compliance and $\mathrm{PaO}_{2} / \mathrm{FiO}_{2}$-ratio were compared in patients with EIT-based PEEP adjustments and in patients with unaltered PEEP. In $28 \%$ of the patients, the difference in EIT-based PEEP and physician-PEEP was clinically relevant; in 36\%, EIT-based PEEP and physician-PEEP were equal. The EIT-based PEEP disagreed with the PEEP settings according to the ARDS network. Adjusting PEEP based upon EIT led to a rapid increase in lung compliance and $\mathrm{PaO}_{2} / \mathrm{FiO}_{2}$-ratio. However, this increase was also observed in the group where the PEEP difference was less than $4 \mathrm{~cm}$ $\mathrm{H}_{2} \mathrm{O}$. We hypothesize that this can be attributed to the alveolar recruitment during the PEEP trial. EIT based individual PEEP setting appears to be a promising method to optimize PEEP in ARDS patients. The clinical impact, however, remains to be established.
\end{abstract}

Keywords Electrical impedance tomography $\cdot$ Acute respiratory distress syndrome $\cdot$ Positive end expiratory pressure · Mechanical ventilation

\section{Abbreviations}

ABG Arterial blood gas

ANOVA Analysis of variance

APACHE Acute physiology and chronic health evaluation

Electronic supplementary material The online version of this article (https://doi.org/10.1007/s10877-018-0164-x) contains supplementary material, which is available to authorized users.

Serge J. H. Heines

s.heines@mumc.nl

Ulrich Strauch

u.strauch@mumc.nl

Marcel C. G. van de Poll

marcel.vande.poll@mumc.nl

Paul M. H. J. Roekaerts

p.roekaerts@mumc.nl

Dennis C. J. J. Bergmans

d.bergmans@mumc.nl

1 Department of Intensive Care, Maastricht University Medical Centre+, P. Debyelaan 25, 6229HX Maastricht, The Netherlands

$\begin{array}{ll}\text { ARDS } & \text { Acute respiratory distress syndrome } \\ \text { BMI } & \text { Body mass index } \\ \text { Cdyn } & \text { Dynamic respiratory system compliance } \\ \text { EIT } & \text { Electrical impedance tomography } \\ \text { ICU } & \text { Intensive care unit } \\ \text { PEEP } & \text { Positive end expiratory pressure } \\ \text { SD } & \text { Standard deviation } \\ \text { VALI } & \text { Ventilator associated lung injury }\end{array}$

2 Department of Surgery, Maastricht University Medical Centre+, P. Debyelaan 25, 6229HX Maastricht, The Netherlands

3 School of Nutrition and Translational Research in Medicine (NUTRIM), Maastricht University, P.O. Box 616, 6200MD Maastricht, The Netherlands

4 Cardiovascular Research Institute Maastricht (CARIM), Maastricht University, P.O. Box 616, 6200MD Maastricht, The Netherlands 


\section{Introduction}

Although mechanical ventilation is a lifesaving therapy, it has some negative side effects such as ventilator associated lung injury (VALI). In the last 15 years, extensive research has been performed on lung protective ventilation. The most important study showing a reduction in mortality in patients with acute respiratory distress syndrome (ARDS) was done by the ARDS network investigators. They highlighted the importance of lung protective ventilation especially by avoiding high tidal volumes and high inspiratory pressures. They proposed a standardized approach to adjust PEEP settings according to changes in oxygen demand [1]. In addition they conceived the ARDS network PEEP/ $\mathrm{FiO}_{2}$ table as a manual to titrate PEEP in ARDS [2]. This approach however, does not take into account individual patient characteristics that determine alveolar recruitment and recruitability such as body mass index (BMI), lung elastance and pulmonary edema [3, 4]. Consequently, a more individualized approach to determine optimal PEEP and tidal volume setting may be desired to optimize the treatment of patients with ARDS. Therefore, strategies like best compliance, stress index and pressure-volume curves were investigated [5-8]. However, these are all based on global parameters which do not exclude regional overdistension, collapse or atelectrauma, especially in patients with ARDS.

Electrical impedance tomography (EIT) is a non-invasive, non-radioactive, bedside imaging tool, providing functional images with a high temporal resolution. These images are dynamic which allows the operator to follow the response of the lungs to a therapeutic intervention on a breath-by-breath basis [9-15]. Because regional overdistension and alveolar collapse can be visualized using EIT it may be superior to the abovementioned global parameters that have been applied in individual PEEP optimization [16]. Despite its theoretical advantages, EIT has not yet been implemented widely in clinical research and practice. This is probably partly due to the complexity of the analysis and interpretation of the data. EIT is performed on regular basis in our institution as part of routine care to adjust and titrate PEEP in patients with ARDS and acute hypoxic respiratory failure. Aim of the present paper is to report on our initial clinical experience using EIT to individualize PEEP setting in mechanically ventilated ARDS patients, and to determine whether EIT guided PEEP is in agreement with physician set PEEP and the PEEP according the ARDS network $\mathrm{PEEP} / \mathrm{FiO}_{2}$ table.

\section{Materials and methods}

\subsection{Patients}

Between January 2015 and August 2016 EIT was performed in 39 adult, mechanically ventilated ARDS patients that were admitted to our 33 bed mixed intensive care unit. Maastricht University Medical Centre+ is a University Hospital which has a total of 715 beds. ARDS was defined according to the Berlin definition [17]. Patient characteristics are presented in Table 1. The selection of the patients was based on the indication for EIT. In our centre we use EIT in patients with difficult mechanical ventilation like patients with ARDS. In our retrospective data we selected 39 patients fulfilling the criteria for ARDS who were sedated and invasively ventilated in a pressure controlled, time-cycled mode (BIPAP or APRV) using an Evita-4 or Evita-XL ventilator (Dräger Medical GmbH, Lübeck, Germany). All patients had no spontaneous breathing activity. Tidal volumes between 6 and $8 \mathrm{ml} / \mathrm{kg}$ predicted body weight were pursued. No strict institutional guidelines on PEEP setting are in use and PEEP was set at the discretion of the treating physician based on clinical information like Cdyn, $\mathrm{PaO}_{2} / \mathrm{FiO}_{2}$-ratio, $\mathrm{BMI}$, hemodynamics, etc. according to a lung protective ventilation strategy until the first EIT assessment.

\subsection{Electric impedance tomography}

EIT analysis was requested by the treating physician and performed by a trained ventilation practitioner (SJHH). An EIT dedicated belt containing 16 electrodes was placed

Table 1 Patient characteristics

\begin{tabular}{ll}
\hline Sex (M/F) & $25 / 14$ \\
APACHE II (SD) & $29(8)$ \\
Age, years (SD) & $65(15)$ \\
BMI (SD) & $26(5)$ \\
Onset ARDS, hours (SD) & $40(58)^{\mathrm{a}}$ \\
Tidal volume ml/kg PBW (SD) & $7.8(2.5)$ \\
$\mathrm{PaO}_{2} / \mathrm{FiO}_{2}, \mathrm{mmHg}(\mathrm{SD})$ & $147(61)$ \\
Type of admission & \\
Pneumonia (\%) & $20(51)$ \\
Sepsis (\%) & $11(28)$ \\
Cardiac arrest (\%) & $3(8)$ \\
Other (\%) & $5(13)$ \\
ARDS & \\
Mild ARDS (\%) & $7(18)$ \\
Moderate ARDS (\%) & $21(54)$ \\
Severe ARDS (\%) & $11(28)$ \\
\hline
\end{tabular}

${ }^{a}$ Hours between fulfilling the ARDS criteria and the EIT measurement. Data are expressed as mean \pm SD 
around the patient's chest at the fourth or fifth intercostal space at the parasternal line, and connected to an EIT monitor (Pulmovista ${ }^{\circledR} 500$, Dräger Medical GmbH, Lübeck, Germany) with a frame rate of $20 \mathrm{~Hz}$. Low-pass filter was set at a cut-off frequency of 50/min. To improve contact between the electrodes and the skin, a delayed onset of the measurement of 5-10 min was used after application of the belt. The EIT monitor was connected to the mechanical ventilator to import ventilator data into the EIT monitor.

EIT measurements were performed during an incremental PEEP trial to an average PEEP level of $18-20 \mathrm{~cm} \mathrm{H}_{2} \mathrm{O}$, followed by a decremental PEEP trial, using steps of $2 \mathrm{~cm}$ $\mathrm{H}_{2} \mathrm{O}$. At each PEEP level change in end expiratory lung impedance (EELI) was evaluated. Driving pressure was constant during the PEEP trial. The decremental trial was stopped when loss of EELI was observed, reflecting derecruitment (Fig. 1) Ventilator settings during the PEEP trial are presented. Afterwards, a short recruitment manoeuvre was performed to select the level of PEEP where EELI does not decrease in the dependent lung regions. This is followed by an offline analysis to evaluate the functional EIT images with dedicated software (EITdiag; Dräger Medical). Using this software, tidal recruitment, alveolar collapse, endinspiratory overdistension and regional compliance could be assessed. Overdistension and CL quantifies the amount of $\mathrm{CL}$ and $\mathrm{OD}$ in the lung by calculating pixel compliance at every PEEP step. Cumulated OD and CL is determined as the percentage change in compliance for each pixel in relation to its "best compliance" as described by Costa et al. [16]. Optimal PEEP was determined as the best compromise between alveolar overdistension and alveolar collapse by offline analysis of changes in regional compliance during each PEEP step in the decremental part of the PEEP trial. This means the best regional compliance to maximize recruitment of the dependent lung and minimize overdistension of nondependent lung areas [18, 19] (Fig. 2).

The algorithm calculates for each pixel the compliance deviation of a given section against the highest compliance, which was present during the entire PEEP trial. Blue to dark blue indicates decrease in respiratory system compliance
Fig. 1 Changes in end-expiratory lung impedance (EELI) values at different decremental PEEP levels reflect the stepwise fall in end-expiratory lung volume (global: overall tidal impedance change; ROI 1 to ROI 4 represent tidal impedance chance from ventral, midventral, mid-dorsal and dorsal region). During the last PEEP step there is a gradual decrease in EELI in ROI 2 reflecting alveolar derecruitment. In ROI 3 and 4 the decrease in EELI starts at earlier PEEP steps (delta-Z tidal impedance variations)

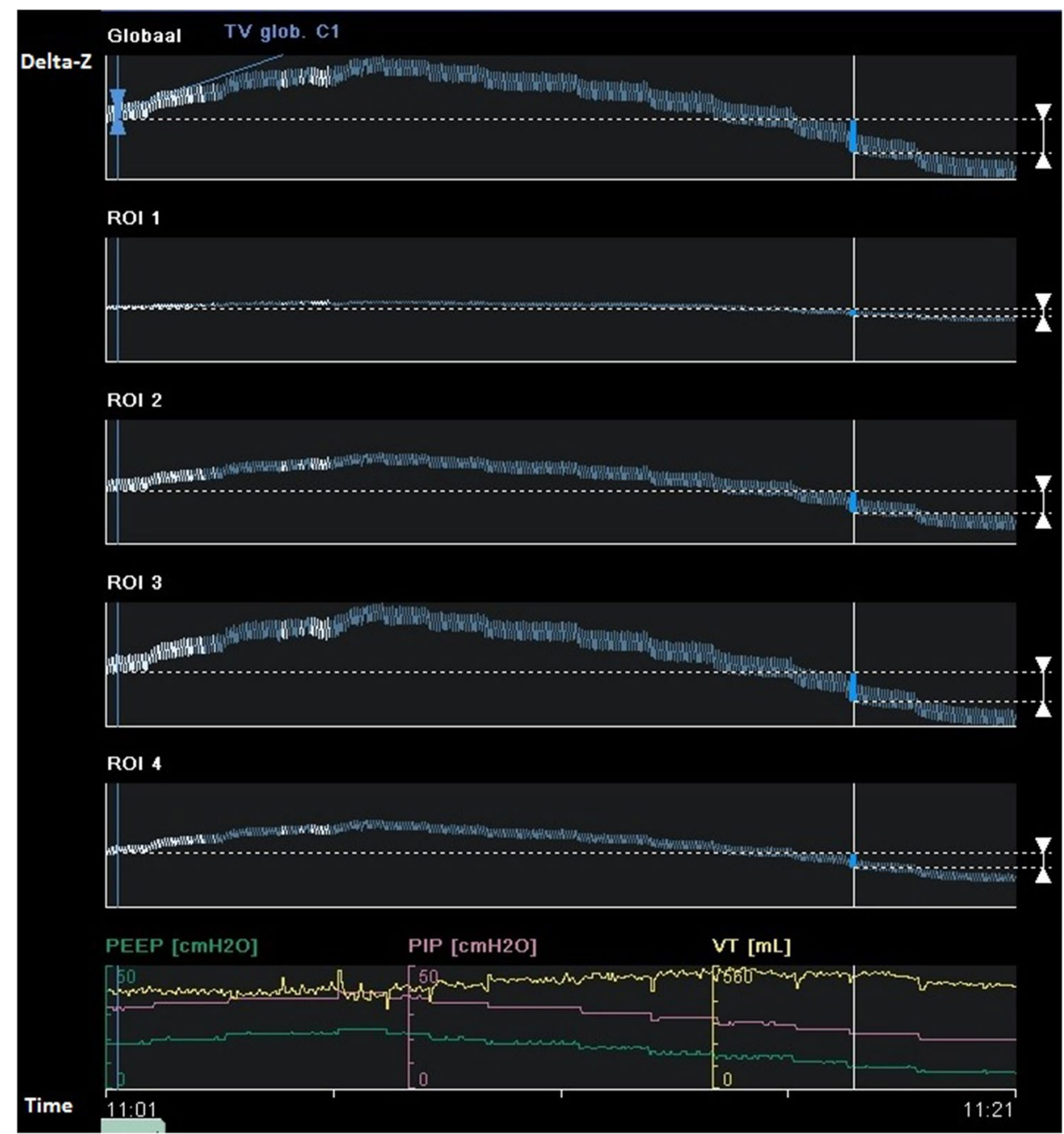




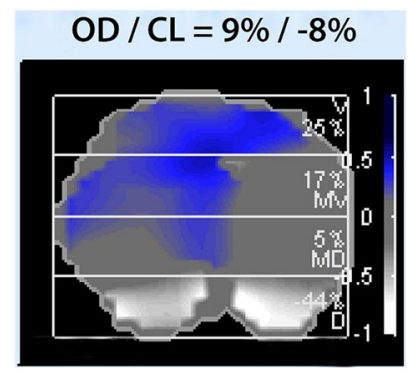

Fig. 2 Alveolar overdistension and alveolar collapse (OD/CL)

(Crs) caused by overdistension, white indicates decrease in Crs caused by airway collapse. Overall overdistension (OD) and collapse (CL) are given as percentage.

\subsection{Clinical application of EIT data and effect evaluation}

Ventilator settings were adjusted to meet optimal PEEP derived from the EIT analysis if actual set PEEP differed from this value. The effect of these PEEP adjustments on oxygenation, $\mathrm{PaO}_{2} / \mathrm{FiO}_{2}$-ratio and Cdyn was assessed by comparing values before and after EIT analysis, and subsequent adjustment of ventilator settings.

Arbitrarily, a difference of $\geq 4 \mathrm{~cm} \mathrm{H}_{2} \mathrm{O}$ between ARDS network table-based PEEP advise and EIT-based PEEP advise was considered to be clinically relevant. To assess the acute effects of EIT based PEEP adjustment on oxygenation and ventilation parameters, patients were divided in a group where pre-EIT PEEP was $<4 \mathrm{~cm} \mathrm{H}_{2} \mathrm{O}$ different from EITadvised PEEP (group A) and a group where the difference between pre-EIT and EIT-advised PEEP was $\geq 4 \mathrm{~cm} \mathrm{H}_{2} \mathrm{O}$ (group B). In addition, we assessed the agreement between EIT-based optimal PEEP level and PEEP level that would have been derived from the ARDS network table [1]. The ARDS network table uses ranges of PEEP, therefore the smallest possible difference in PEEP according the ARDS network table PEEP and EIT-based PEEP advise was used. For example, if the PEEP according the ARDS network table should be in the range of $10-14 \mathrm{~cm} \mathrm{H}_{2} \mathrm{O}$, and EIT PEEP determined to be $16 \mathrm{~cm} \mathrm{H}_{2} \mathrm{O}$, the difference is $2 \mathrm{~cm} \mathrm{H}_{2} \mathrm{O}$.

\subsection{Statistics}

Data are presented as a number (percentage) for categorical variables and as mean \pm standard deviation (SD) or median and interquartile range for continuous variables where appropriate. A paired sample $t$ test was used to assess normally distributed data and Mann-Whitney $U$ test to assess data that were not distributed normally. A p value $<0.05$ (twotailed) was considered to indicate statistical significance. Two-way ANOVA was used to compare the mean values of
Table 2 Ventilator settings during the PEEP trial

\begin{tabular}{lc}
\hline Delta-P $\left(\mathrm{cm} \mathrm{H}_{2} \mathrm{O}\right)$ & $14.1( \pm 4.5)$ \\
RR (breaths/min) & $24.2( \pm 8.8)$ \\
Tv high PEEP $(\mathrm{ml})$ & $378( \pm 135)$ \\
Tv optimal PEEP $(\mathrm{ml})$ & $553( \pm 183)$ \\
\hline
\end{tabular}

Data are expressed as mean $\pm \mathrm{SD}$ (Delta- $P$ delta pressure, $R R$ respiratory rate, Tv high PEEP tidal volume at the highest PEEP level, $T v$ optimal PEEP tidal volume at the optimal PEEP level according EIT)

Cdyn and the $\mathrm{PaO}_{2} / \mathrm{FiO}_{2}$-ratio before and after EIT measurement. A p-value $<0.05$ was considered statistical significant. Mann-Whitney $U$ test was used to compare the median values between group A and group B. Individual pair-wise differences between the three PEEP methods were presented by Bland-Altman plots where the size of the dot is an indicator of the incidence of the value. The Bland-Altman plots were made with MATLAB 2017a (Mathworks, Natick, MA). All statistical analyses were performed using SPSS version 23 software (IBM SPSS, Armonk, NY). GraphPad Prism version 5.03 software (GraphPad Software, inc. La Jolla, CA, USA) was used to generate graphs of the individual EELI tracings during the PEEP trial.

\subsection{Ethics}

EIT is used as part of routine care in our department and indications for EIT were determined based upon clinical grounds. The ethics committee of the Maastricht University Medical Centre+ approved the utilization of the collected data for scientific evaluation and individual informed consent was waived (METC 15-4-186).

\section{Results}

\subsection{Feasibility of routine clinical EIT application in ARDS}

EIT image acquisition and off-line data analysis was successful in all patients. During the incremental and decremental PEEP-trial no complications such as desaturation, hemodynamic instability or pneumothorax occurred. Ventilator settings during the PEEP trial are presented in Table 2.

\subsection{Agreement between set PEEP, EIT-based PEEP advise and ARDS network-based PEEP advise}

PEEP was set to $11.7 \pm 2.6 \mathrm{~cm} \mathrm{H}_{2} \mathrm{O}$ in all patients. According to EIT-analysis optimal PEEP would have been $11.3 \pm 3.1 \mathrm{~cm} \mathrm{H}_{2} \mathrm{O}$ for the entire population which was not significantly different from actual set PEEP $(p=0.305)$. Actual set PEEP was significant lower in mild versus 
Table 3 Actual set PEEP and "optimal PEEP" based on EIT advise

\begin{tabular}{lcc}
\hline & Actual set PEEP & EIT based PEEP advise \\
\hline Total $(\mathrm{n}=39)$ & $11.7( \pm 2.6)$ & $11.3( \pm 3.1)$ \\
Mild ARDS $(\mathrm{n}=7)$ & $9.7( \pm 1.8)$ & $9.4( \pm 2.2)^{\beta}$ \\
Moderate ARDS $(\mathrm{n}=21)$ & $12.1( \pm 2.6)^{*}$ & $10.9( \pm 2.7)$ \\
Severe ARDS $(\mathrm{n}=11)$ & $12.4( \pm 2.8)^{\alpha}$ & $13.3( \pm 3.6)^{\gamma}$ \\
\hline
\end{tabular}

$* \mathrm{p}=0.032$ mild versus moderate

${ }^{\alpha} \mathrm{p}=0.042$ mild versus severe

${ }^{\beta} \mathrm{p}=0.023$ mild versus severe

$\gamma_{p}=0.039$ moderate versus severe

Table 4 Baseline characteristics of ARDS patients between group A and group $B$

\begin{tabular}{lccc}
\hline & $\begin{array}{l}\text { Group A } \\
(\mathrm{n}=28)\end{array}$ & $\begin{array}{l}\text { Group B } \\
(\mathrm{n}=11)\end{array}$ & p-value \\
\hline $\mathrm{PEEP}\left(\mathrm{cm} \mathrm{H}_{2} \mathrm{O}\right)$ & $12(4)$ & $12(6)$ & 0.470 \\
$\mathrm{FiO}_{2}$ & $0.6(0.4)$ & $0.6(0.45)$ & 0.355 \\
$\mathrm{PaO}_{2} / \mathrm{FiO}_{2}$-ratio & $136(14)$ & $131(11)$ & 0.779 \\
$\mathrm{Cdyn}\left(\mathrm{ml} / \mathrm{cm} \mathrm{H}_{2} \mathrm{O}\right)$ & $44(30)$ & $34(32)$ & 0.075 \\
\hline
\end{tabular}

moderate and mild versus severe ARDS ( $\mathrm{p}=0.032$ and $\mathrm{p}=0.042$ respectively). EIT advised PEEP was significantly higher in severe versus mild and in severe versus moderate ARDS ( $\mathrm{p}=0.023$ and $\mathrm{p}=0.039$ respectively) (Table 3 ).
Actual set PEEP and "optimal PEEP" based on EIT advise. Actual set PEEP was significant lower in mild versus moderate and mild versus severe ARDS $(* p=0.032$ and ${ }^{\alpha} \mathrm{p}=0.042$ respectively). EIT advised PEEP was significantly higher in severe versus mild and in severe versus moderate ARDS $\left({ }^{\beta} p=0.023\right.$ and ${ }^{\gamma} p=0.039$ respectively). Data are expressed as mean $\pm \mathrm{SD}$ (Student's $t$ test).

Baseline characteristics of ARDS patients between group A and group B are presented in Table 4. In 14 out of 39 (36\%) of the cases, EIT-based PEEP advise was equal to the actual PEEP level set by the treating physician. In 11 out of $39(28 \%)$ of the cases the difference between EITbased PEEP advise and set PEEP level was $\geq 4 \mathrm{~cm} \mathrm{H}_{2} \mathrm{O}$. We observed no systematic higher or lower estimation of desirable PEEP level using one of either approaches. The (dis)agreement between physician set PEEP and EIT advised PEEP is displayed in Fig. 3.

Baseline patient characteristics of ARDS patients where pre-EIT PEEP was $<4 \mathrm{~cm} \mathrm{H}_{2} \mathrm{O}$ different from EIT-advised PEEP (group A) and a group where the difference between pre-EIT and EIT-advised PEEP was $\geq 4 \mathrm{~cm} \mathrm{H}_{2} \mathrm{O}$ (group B). Data are expressed as median (interquartile range), Mann-Whitney $U$ test.

EIT-based PEEP advise was in agreement with the PEEP level advised by the ARDS network table only in 12 out of 39 cases (31\%) (Fig. 4).

In 19 out of $39(49 \%)$ of the cases, EIT-based PEEP advise was equal to the PEEP level based on best Cdyn. In
Fig. 3 Bland Altman plot of differences in PEEP between EIT guided PEEP and the PEEP set by the physician. The size of the dot is an indicator for the incidence of the value. The red dashed line indicates a PEEP difference of $4 \mathrm{~cm} \mathrm{H}_{2} \mathrm{O}$

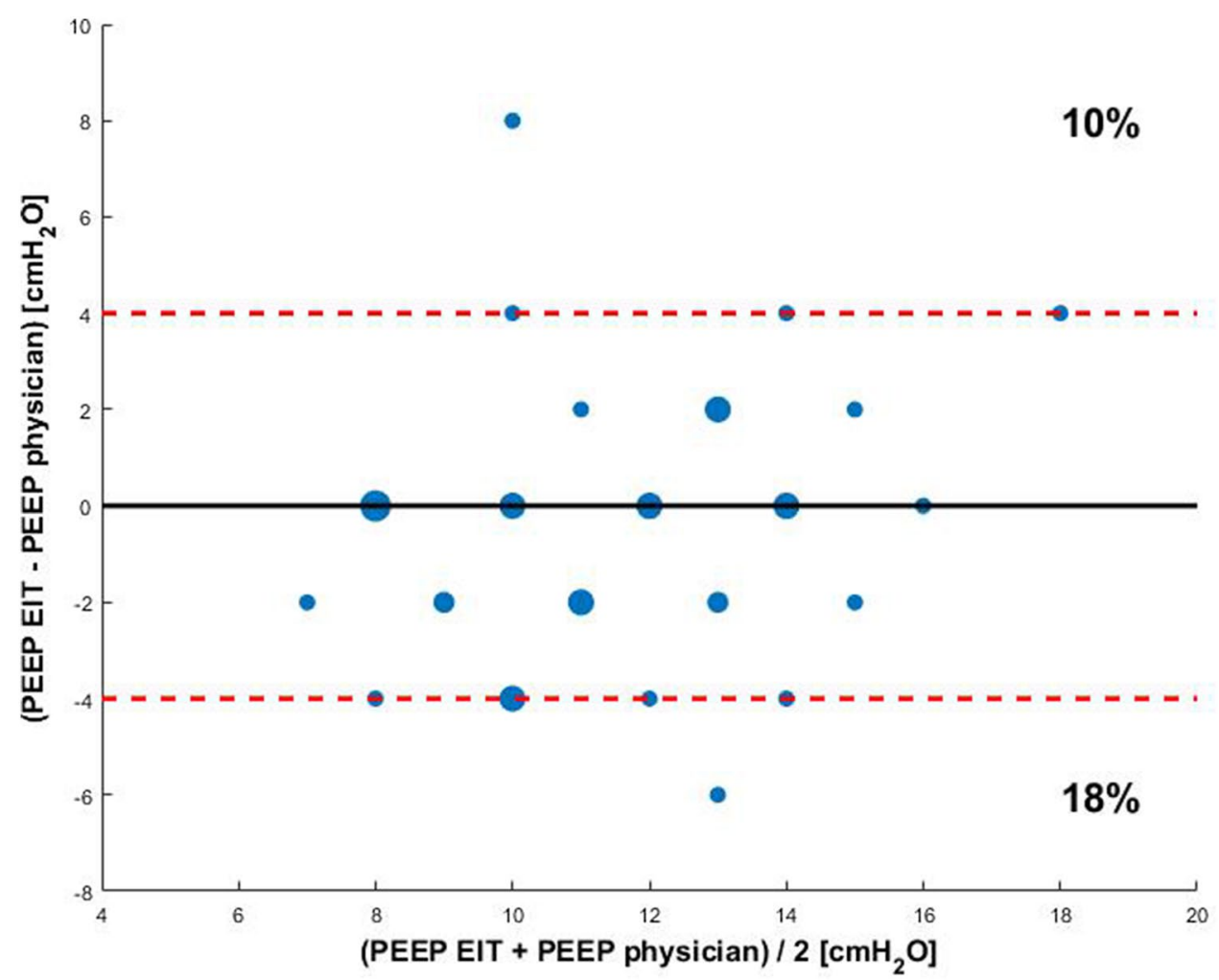


Fig. 4 Bland Altman plot of differences in PEEP between the ARDS network table and EIT guided PEEP. The size of the dot is an indicator for the incidence of the value. The red dashed line indicates a PEEP difference of $4 \mathrm{~cm} \mathrm{H}_{2} \mathrm{O}$

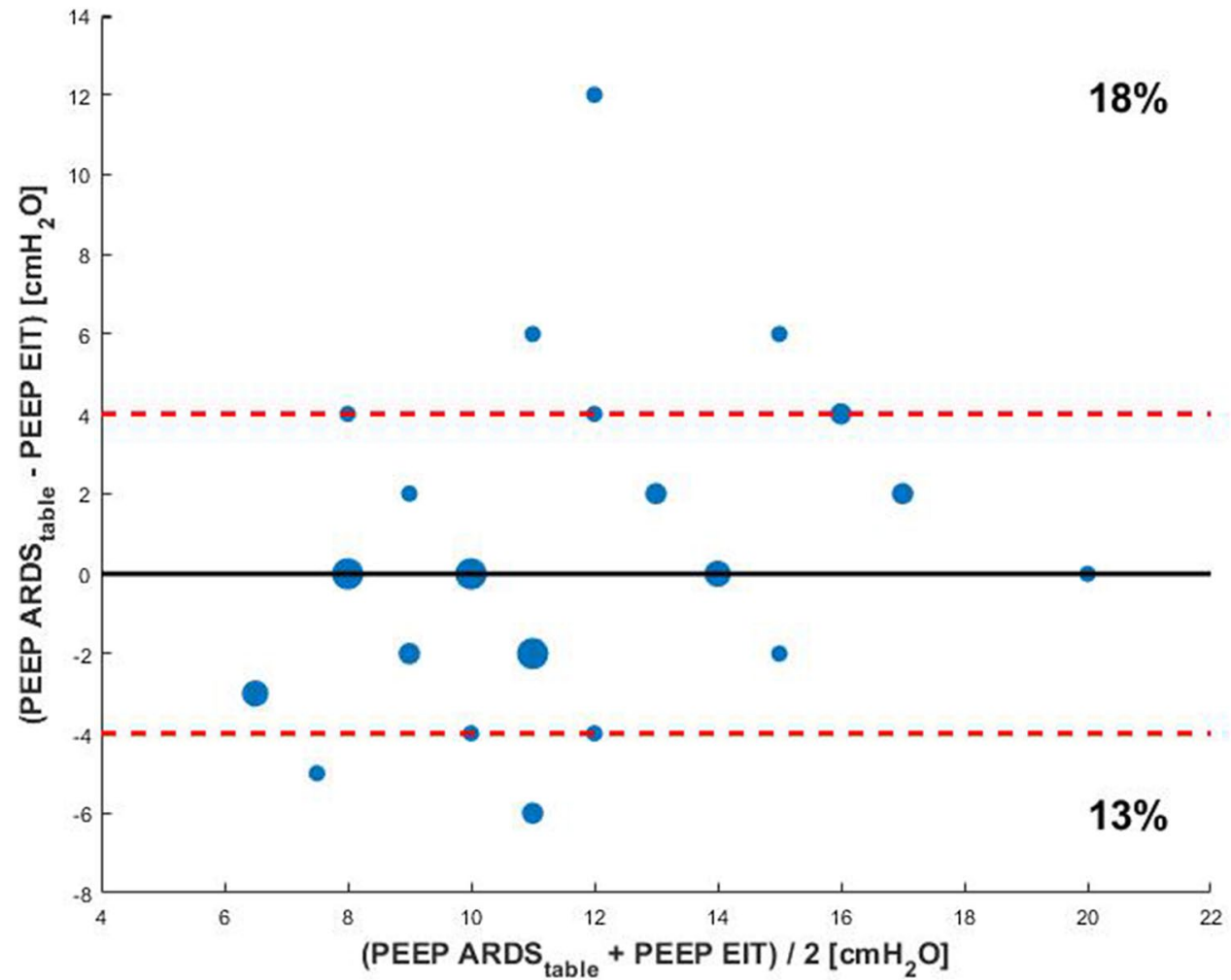

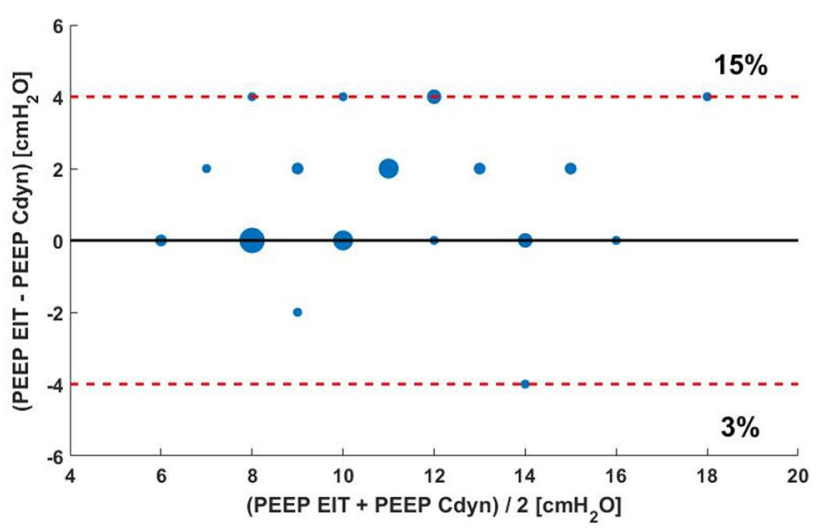

Fig. 5 Bland Altman plot of differences in PEEP between EIT guided PEEP and PEEP based on best Cdyn. The size of the dot is an indicator for the incidence of the value. The red dashed line indicates a PEEP difference of $4 \mathrm{~cm} \mathrm{H}_{2} \mathrm{O}$

7 out of $39(18 \%)$ of the cases the difference between EITbased PEEP best Cdyn PEEP level was $\geq 4 \mathrm{~cm} \mathrm{H}_{2} \mathrm{O}$ (Fig. 5).

\subsection{Acute clinical effects of EIT-guided PEEP adjustment on $\mathrm{PaO}_{2} / \mathrm{FiO}_{2}$-ratio and dynamic respiratory system compliance}

As described in the methods section, patients were divided in two groups: a group where pre-EIT PEEP was $<4 \mathrm{~cm}$ $\mathrm{H}_{2} \mathrm{O}$ different from EIT-advised PEEP (group A) and a group where the difference between pre-EIT and EITadvised PEEP was $\geq 4 \mathrm{~cm} \mathrm{H}_{2} \mathrm{O}$ (group B). At baseline, there were no significant differences in $\mathrm{PaO}_{2} / \mathrm{FiO}_{2}$-ratio between group A and group $\mathrm{B}(\mathrm{p}=0.779)$. Dynamic respiratory system compliance was also not different between groups $(\mathrm{p}=0.075)$. After EIT guided PEEP adjustment both $\mathrm{PaO}_{2} /$ $\mathrm{FiO}_{2}$-ratio and Cdyn increased significantly in both groups $(\mathrm{p}<0.001)$. However, for both these parameters, there were no significant differences in effect size between both groups ( $p=0.894$ and $p=0.151$ respectively). Effects of EIT-guided PEEP adjustment on $\mathrm{PaO}_{2} / \mathrm{FiO}_{2}$-ratio and Cdyn are presented in Figs. 6 and 7.

Individual EELI tracings from three patients during the PEEP trial in four regions of interest are presented in Figs. 8, 9 and 10.

\section{Discussion}

This is the first study reporting on the results of routine clinical use of EIT to guide PEEP setting in mechanically ventilated ARDS patients. We found that in approximately two-thirds of the patients, EIT guided PEEP differed from physicians' set PEEP and from ARDS network suggested PEEP. In approximately one-third of the patients the PEEP difference was even $4 \mathrm{~cm} \mathrm{H}_{2} \mathrm{O}$ or more.

To this point there is no definition for optimal PEEP, there is no consensus whether to use high PEEP levels to 


\section{Cdyn}

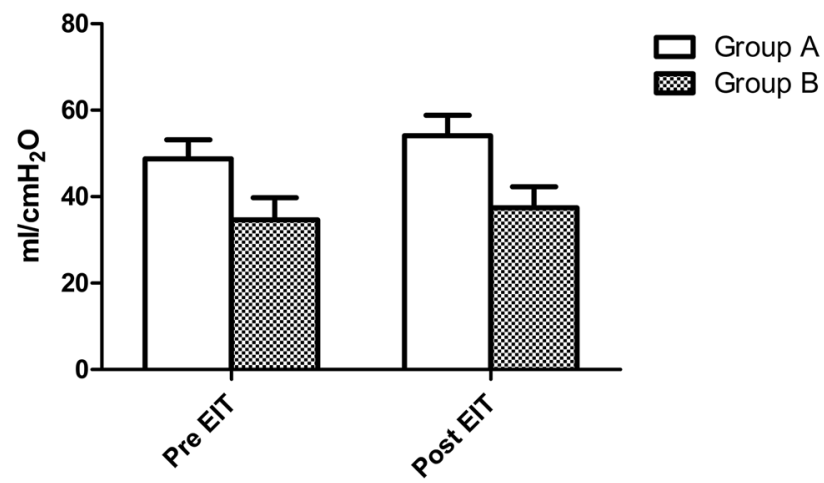

Fig. 6 Acute changes in Cdyn in 39 mechanically ventilated ARDS patients after EIT in the group where pre-EIT PEEP was $<4 \mathrm{~cm} \mathrm{H}_{2} \mathrm{O}$ (group A) different from EIT-advised PEEP and a group where the difference between pre-EIT and EIT-advised PEEP was $\geq 4 \mathrm{~cm} \mathrm{H}_{2} \mathrm{O}$ (group B). There was a significant increase in the Cdyn $(\mathrm{p}<0.001)$, however this increase was not significantly different between both groups ( $\mathrm{p}=0.151$ for interaction, 2-way ANOVA)

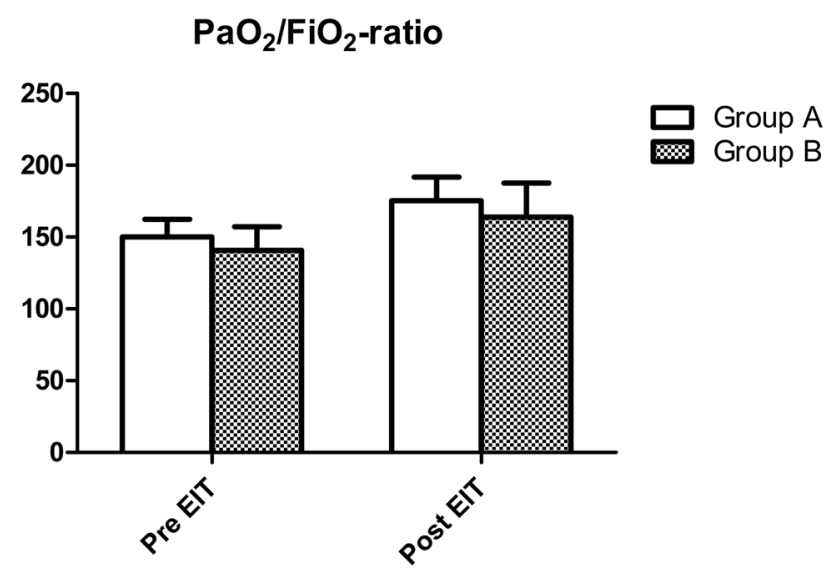

Fig. 7 Acute changes in $\mathrm{PaO}_{2} / \mathrm{FiO}_{2}$-ratio in 39 mechanically ventilated ARDS patients after EIT in the group where pre-EIT PEEP was $<4 \mathrm{~cm} \mathrm{H}_{2} \mathrm{O}$ (group A) different from EIT-advised PEEP and a group where the difference between pre-EIT and EIT-advised PEEP was $\geq 4 \mathrm{~cm} \mathrm{H}_{2} \mathrm{O}$ (group B). There was a significant increase in the $\mathrm{PaO}_{2} /$ $\mathrm{FiO}_{2}$-ratio $(\mathrm{p}<0.001)$, however this increase was not significantly different between both groups ( $p=0.894$ for interaction, 2-way ANOVA)

avoid all lung collapse or if overdistension is a contributive factor to VALI. At this time there are different views on the matter. Lachmann introduced the "open lung concept" applying higher levels of PEEP to keep the lungs open while others focus their ventilator settings on avoiding overdistension secondary to high PEEP levels, or define optimal PEEP as the lowest level of alveolar overdistension and collapse [19-22]. The PEEP level using a more open lung approach with CL less than 3 or $1 \%$ are presented as supplementary material.

\section{Patient 7}

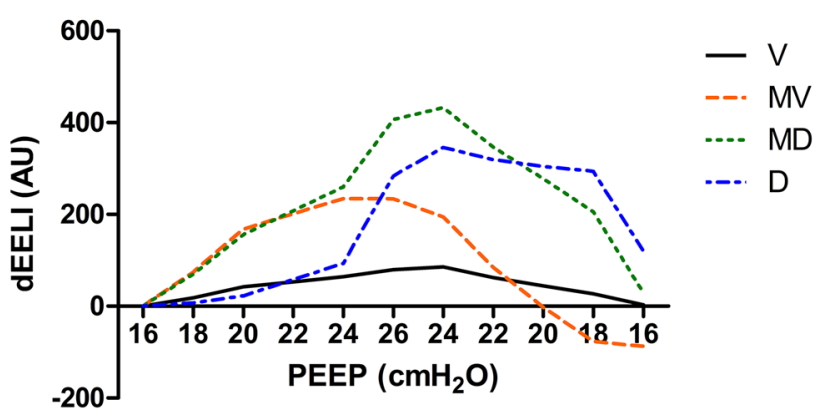

Fig. 8 Changes in EELI in four regions of regions of interest during the PEEP trial ( $V$ ventral, $M V$ mid-ventral, $M D$ mid-dorsal, $D$ dorsal). There is a large drop of EELI in the mid-dorsal and dorsal region when PEEP was decreased below $18 \mathrm{~cm} \mathrm{H}_{2} \mathrm{O}$. PEEP was set at $20 \mathrm{~cm}$ $\mathrm{H}_{2} \mathrm{O}$ in this patient (dEELI delta-end expiratory lung impedance, $A U$ arbitrary units)

\section{Patient 13}

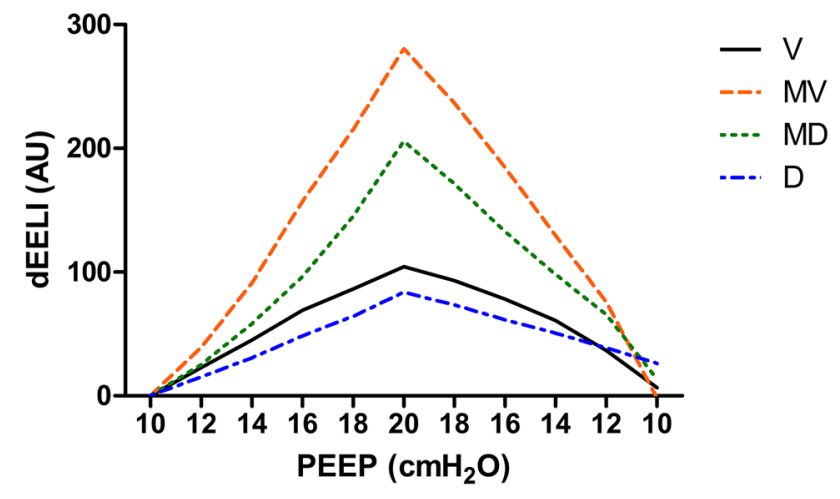

Fig. 9 Changes in EELI in four regions of regions of interest during the PEEP trial ( $V$ ventral, $M V$ mid-ventral, $M D$ mid-dorsal, $D$ dorsal). At the end of the PEEP trial EELI returns to baseline. PEEP was set at $10 \mathrm{~cm} \mathrm{H}_{2} \mathrm{O}$ in this patient (dEELI delta-end expiratory lung impedance, $A U$ arbitrary units)

The present study shows a clear difference in set PEEP comparing the three methods (PEEP according to EIT, ARDS network table and clinician-based PEEP), without proving that the one method is better than the other. From a physiological point of view, an individualized approach which adjusts delta pressure, PEEP and respiratory rate to a patients' specific lung mechanics seems appropriate. In literature, different responses to PEEP steps are found between different patient groups but also within groups [23]. The PEEP/FiO 2 -table from the ARDS network study is a generalized PEEP approach, not adapted to the patients specific characteristics, which might explain the differences between EIT guided PEEP in our study group versus ARDS network table's guided PEEP. 


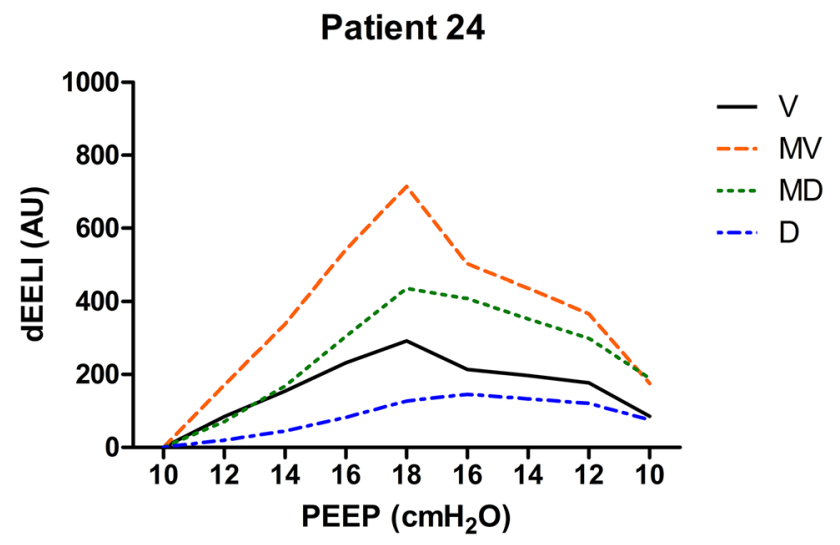

Fig. 10 Changes in EELI in four regions of regions of interest during the PEEP trial ( $V$ ventral, $M V$ mid-ventral, $M D$ mid-dorsal, $D$ dorsal). At the end of the PEEP trial EELI is higher compared to baseline. PEEP was set at $10 \mathrm{~cm} \mathrm{H}_{2} \mathrm{O}$ in this patient (dEELI delta-end expiratory lung impedance, $A U$ arbitrary units)

Using changes in respiratory system compliance during a PEEP trial seems to be an useful alternative to determine the optimal PEEP as described earlier [7, 24]. The present study shows that in almost $50 \%$ of the patients EIT-guided PEEP was equal to the PEEP level which corresponds with the best Cdyn. However, in $18 \%$ of the patients the difference in optimal PEEP was $4 \mathrm{~cm} \mathrm{H}_{2} \mathrm{O}$, however never bigger. The advantage of EIT is that it can identify the level of PEEP where derecruitment begins, even if global Cdyn still increases due to some relief of OD, which can also be visualised with EIT.

Changes in EELI have different patterns in different patients as shown in Figs. 8, 9, 10. The increase in EELI was not always preferentially distributed to the non-dependent lung regions as Lowhagen et al. showed before [25]. In some patients EELI is increased after the PEEP trial reflecting alveolar recruitment. Changes in EELI can only be used to estimate changes in end expiratory lung volume since EIT is measured at only one level just above the diaphragm. However, there is a moderate agreement between end expiratory lung volume and the volume calculated from changes in EELI [26].

Global measures of oxygenation or respiratory system mechanics are usually applied as reference to adjust mechanical ventilation on an individual basis. These global measures may produce misleading information by 'averaging', they do not exclude overdistension, tidal recruitment or collapse in different lung regions [27]. Radiological images are very useful as a diagnostic tool for pulmonary edema, pleural effusion, pneumothorax, atelectasis, etc., but they are limited because only one point in time is obtained. Changes that occur dynamically will be missed. Other methods to determine PEEP like low-flow pressure-volume curves, stress-index, oesophageal pressure, $\mathrm{PEEP} / \mathrm{FiO}_{2}$-tables do not take into account regional overdistension or collapse, they lack information on ventilation distribution. Only CTscan, with the exception of EIT, can provide this information but still is one sample in time. An individualized approach while monitoring for regional overdistension, atelectrauma and alveolar collapse is probably superior to an approach not taken into account the individual characteristics of each patient. EIT offers the ability to monitor regional respiratory mechanics and monitor its clinical course as compared to the global measures of respiratory system mechanics that are commonly clinically assessed at the bedside to guide the ventilator settings [27]. Also, EIT can monitor regional compliance. During changes in PEEP, the interaction between dependent and non-dependent regions can be disclosed [23]. The assessment of regional overdistension and atelectasis can be visualized using EIT during changes in PEEP and has been validated by histological examination of lung tissue [28]. An animal study used by Wolf et al. was the first prospective study wherein EIT guided ventilator settings were used [18], followed by other animal and human studies $[22,29]$.

In the present study we assessed short term clinical effects of PEEP adjustment. Whereas PEEP is an important determinant of oxygenation and compliance in the short term, the effects of inadequate ventilation may only become overt weeks to months after the acute phase of ARDS in the form of VALI. EIT may play an important role in the prevention of VALI by minimizing repetitive alveolar collapse or overdistension. Such long term effects can only be studied in a prospective randomized trial with long-term follow-up.

After PEEP-adjustment according to the EIT findings, we observed a significant direct increase in oxygenation and dynamic compliance. However, this increase was also observed in the group where the PEEP difference was less than $4 \mathrm{~cm} \mathrm{H}_{2} \mathrm{O}$ (group A). We hypothesize that the incremental and decremental PEEP trial that was performed during the EIT study had similar effects as a lung recruitment manoeuvre. Due to the study method we were not able to extend our comparative follow up afterwards since PEEP remained at the level set according to EIT-advise. This eliminated the possibility to compare ventilation and oxygenation between patients who are treated using EIT guidance and a control group where an alternative method of PEEP setting was applied.

EIT analyses depend on the experience of the operator and thus are vulnerable in terms of bias. Moreover, not visualizing ventilation distribution in the whole lung is a drawback of EIT measurements. The impedance changes are measured in a lens-shaped slice of the thorax with an increase in thickness of approximately $12 \mathrm{~cm}$ in the central region of the body [30]. The position of the belt effects the EIT measurements. In mechanically ventilated patients, the PEEP level with the best regional compliance is different 
for the dependent and nondependent lung regions as well as for the caudal and cranial lung levels. When decreasing PEEP while EIT is measured at the caudal lung level, the diaphragm might enter the measurement field causing artefacts and unreliable results [31]. Therefore, new analysis tools and algorithms that extract clinically relevant information and reduce the clinicians workload are necessary to facilitate the clinical application and implementation in daily care of EIT. In this study we started with an incremental PEEP trial at low PEEP, hereby artefacts caused by diaphragm displacement could be detected and the position of the belt corrected.

To study the effect of EIT guidance in PEEP optimization, prospective randomized trials comparing different alternative approaches such as the ARDS network table to determine PEEP settings with EIT in ARDS patients are warranted. Especially since this study showed a very limited agreement between PEEP levels advised by the ARDS network table and by EIT.

\section{Conclusions}

This is a unique series of patients with ARDS in which EIT is used to guide ventilatory settings in practice. Our single center experience shows EIT can be used in the clinical setting. As regional overdistension and alveolar collapse can be visualized using EIT, it is a promising tool which has a large potential for becoming the golden standard as a bedside patient-tailored ventilatory setting tool. A randomized controlled trial with long term outcome effects is required to see if EIT guided PEEP setting actually improves clinical outcome.

Open Access This article is distributed under the terms of the Creative Commons Attribution 4.0 International License (http://creativeco mmons.org/licenses/by/4.0/), which permits unrestricted use, distribution, and reproduction in any medium, provided you give appropriate credit to the original author(s) and the source, provide a link to the Creative Commons license, and indicate if changes were made.

\section{References}

1. The Acute Respiratory Distress Syndrome Network Ventilation with lower tidal volumes as compared with traditional tidal volumes for acute lung injury and the acute respiratory distress syndrome. N Engl J Med. 2000;342(18):1301-8.

2. Kallet RH, Branson RD. Do the NIH ARDS clinical trials network $\mathrm{PEEP} / \mathrm{FiO}_{2}$ tables provide the best evidence-based guide to balancing PEEP and $\mathrm{FiO}_{2}$ settings in adults? Respir Care. 2007;52(4):461-75.

3. Pelosi P, Ravagnan I, Giurati G, Panigada M, Bottino N, Tredici S, et al. Positive end-expiratory pressure improves respiratory function in obese but not in normal subjects during anesthesia and paralysis. Anesthesiology. 1999;91(5):1221-31.
4. Chiumello D, Carlesso E, Cadringher P, Caironi P, Valenza F, Polli F, et al. Lung stress and strain during mechanical ventilation for acute respiratory distress syndrome. Am J Respir Crit Care Med. 2008;178(4):346-55.

5. Crotti S, Mascheroni D, Caironi P, Pelosi P, Ronzoni G, Mondino M, et al. Recruitment and derecruitment during acute respiratory failure: a clinical study. Am J Respir Crit Care Med. 2001;164(1):131-40.

6. Pelosi P, Goldner M, McKibben A, Adams A, Eccher G, Caironi $\mathrm{P}$, et al. Recruitment and derecruitment during acute respiratory failure: an experimental study. Am J Respir Crit Care Med. 2001;164(1):122-30.

7. Pintado MC, de Pablo R, Trascasa M, Milicua JM, Rogero S, Daguerre $M$, et al. Individualized PEEP setting in subjects with ARDS: a randomized controlled pilot study. Respir Care. 2013;58(9):1416-23.

8. Grasso S, Terragni P, Mascia L, Fanelli V, Quintel M, Herrmann $\mathrm{P}$, et al. Airway pressure-time curve profile (stress index) detects tidal recruitment/hyperinflation in experimental acute lung injury. Crit Care Med. 2004;32(4):1018-27.

9. Nestler C, Simon P, Petroff D, Hammermuller S, Kamrath D, Wolf $\mathrm{S}$, et al. Individualized positive end-expiratory pressure in obese patients during general anaesthesia: a randomized controlled clinical trial using electrical impedance tomography. Br J Anaesth. 2017;119(6):1194-205.

10. Eronia N, Mauri T, Maffezzini E, Gatti S, Bronco A, Alban L, et al. Bedside selection of positive end-expiratory pressure by electrical impedance tomography in hypoxemic patients: a feasibility study. Ann Intensive Care. 2017;7(1):76.

11. Yun L, He HW, Moller K, Frerichs I, Liu D, Zhao Z. Assessment of lung recruitment by electrical impedance tomography and oxygenation in ARDS patients. Medicine (Baltimore). 2016;95(22):e3820.

12. Blankman P, Shono A, Hermans BJ, Wesselius T, Hasan D, Gommers D. Detection of optimal PEEP for equal distribution of tidal volume by volumetric capnography and electrical impedance tomography during decreasing levels of PEEP in post cardiacsurgery patients. Br J Anaesth. 2016;116(6):862-9.

13. He X, Jiang J, Liu Y, Xu H, Zhou S, Yang S, et al. Electrical impedance tomography-guided PEEP titration in patients undergoing laparoscopic abdominal surgery. Medicine (Baltimore). 2016;95(14):e3306.

14. Long Y, Liu DW, He HW, Zhao ZQ. Positive end-expiratory pressure titration after alveolar recruitment directed by electrical impedance tomography. Chin Med J (Engl). 2015;128(11):1421-7.

15. Spadaro S, Mauri T, Bohm SH, Scaramuzzo G, Turrini C, Waldmann AD, et al. Variation of poorly ventilated lung units (silent spaces) measured by electrical impedance tomography to dynamically assess recruitment. Crit Care. 2018;22(1):26.

16. Costa EL, Borges JB, Melo A, Suarez-Sipmann F, Toufen C Jr, Bohm SH, et al. Bedside estimation of recruitable alveolar collapse and hyperdistension by electrical impedance tomography. Intensive Care Med. 2009;35(6):1132-7.

17. Force ADT, Ranieri VM, Rubenfeld GD, Thompson BT, Ferguson ND, Caldwell E, et al. Acute respiratory distress syndrome: the Berlin Definition. JAMA. 2012;307(23):2526-33.

18. Wolf GK, Gomez-Laberge C, Rettig JS, Vargas SO, Smallwood $\mathrm{CD}$, Prabhu SP, et al. Mechanical ventilation guided by electrical impedance tomography in experimental acute lung injury. Crit Care Med. 2013;41(5):1296-304.

19. Karsten J, Grusnick C, Paarmann H, Heringlake M, Heinze H. Positive end-expiratory pressure titration at bedside using electrical impedance tomography in post-operative cardiac surgery patients. Acta Anaesthesiol Scand. 2015;59(6):723-32. 
20. Papadakos PJ, Lachmann B. The open lung concept of alveolar recruitment can improve outcome in respiratory failure and ARDS. Mt Sinai J Med. 2002;69(1-2):73-7.

21. Retamal J, Bugedo G, Larsson A, Bruhn A. High PEEP levels are associated with overdistension and tidal recruitment/derecruitment in ARDS patients. Acta Anaesthesiol Scand. 2015;59(9):1161-9.

22. Franchineau G, Brechot N, Lebreton G, Hekimian G, Nieszkowska A, Trouillet JL, et al. Bedside contribution of electrical impedance tomography to setting positive end-expiratory pressure for extracorporeal membrane oxygenation-treated patients with severe acute respiratory distress syndrome. Am J Respir Crit Care Med. 2017;196(4):447-57.

23. Bikker IG, Leonhardt S, Reis Miranda D, Bakker J, Gommers D. Bedside measurement of changes in lung impedance to monitor alveolar ventilation in dependent and non-dependent parts by electrical impedance tomography during a positive end-expiratory pressure trial in mechanically ventilated intensive care unit patients. Crit Care. 2010;14(3):R100.

24. Suarez-Sipmann F, Bohm SH, Tusman G, Pesch T, Thamm O, Reissmann $\mathrm{H}$, et al. Use of dynamic compliance for open lung positive end-expiratory pressure titration in an experimental study. Crit Care Med. 2007;35(1):214-21.

25. Lowhagen K, Lundin S, Stenqvist O. Regional intratidal gas distribution in acute lung injury and acute respiratory distress syndrome-assessed by electric impedance tomography. Minerva Anestesiol. 2010;76(12):1024-35.
26. Bikker IG, Leonhardt S, Bakker J, Gommers D. Lung volume calculated from electrical impedance tomography in ICU patients at different PEEP levels. Intensive Care Med. 2009;35(8):1362-7.

27. Frerichs I, Amato MB, van Kaam AH, Tingay DG, Zhao Z, Grychtol B, et al. Chest electrical impedance tomography examination, data analysis, terminology, clinical use and recommendations: consensus statement of the TRanslational EIT developmeNt stuDy group. Thorax. 2016. https://doi.org/10.1136/thora xjnl-2016-208357

28. Gomez-Laberge C, Rettig JS, Smallwood CD, Boyd TK, Arnold $\mathrm{JH}$, Wolf GK. Interaction of dependent and non-dependent regions of the acutely injured lung during a stepwise recruitment manoeuvre. Physiol Meas. 2013;34(2):163-77.

29. Hochhausen N, Biener I, Rossaint R, Follmann A, Bleilevens C, Braunschweig T, et al. Optimizing PEEP by electrical impedance tomography in a porcine animal model of ARDS. Respir Care. 2017;62(3):340-9.

30. Karsten J, Stueber T, Voigt N, Teschner E, Heinze H. Influence of different electrode belt positions on electrical impedance tomography imaging of regional ventilation: a prospective observational study. Crit Care. 2016;20(1):3.

31. Bikker IG, Preis C, Egal M, Bakker J, Gommers D. Electrical impedance tomography measured at two thoracic levels can visualize the ventilation distribution changes at the bedside during a decremental positive end-expiratory lung pressure trial. Crit Care. 2011;15(4):R193. 